\title{
Kasabach-Merritt phenomenon in a neonatal kaposiform haemangioendothelioma
}

\author{
Veronica Mardegan, ${ }^{1}$ Nicoletta Doglioni, ${ }^{1}$ Giuseppe De Bernardo, ${ }^{2}$ \\ Daniele Trevisanuto ${ }^{1}$
}

CrossMark

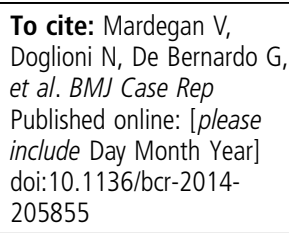

\section{Correspondence to} Dr Giuseppe De Bernardo, debernardo.giuseppe@alice.it

Accepted 23 July 2014

\begin{abstract}
'Department of Women's and
Children's Health, University of
'Department of Women's and
Children's Health, University of Padua, Azienda Ospedaliera di Padova, Padua, Italy ${ }^{2}$ Department of TIN e Neonatologia, AORN Santobono Pausilipon, Napoli, Italy
\end{abstract}

\section{DESCRIPTION}

A female infant was born at $27^{+5}$ weeks of gestation through emergency caesarean section, performed because of an acute increase of a compressive thoracic malformation diagnosed at the 20th gestational week.

At birth, two enormous violaceous masses extending to thorax and superior limbs were observed (figure 1). The infant was immediately intubated and transfused because of severe anaemia. A compressive bandage on masses was performed to decrease the risk of bleeding. Angio-CT confirmed the presence of voluminous masses surrounding the thorax (figure 2).

A sclerosant approach and chemotherapy were not feasible due to the disease extent and location, and prematurity of the newborn. Prednisone therapy was started from the first day of life, but it was ineffective. Surgical removal was proposed, but the infant's family refused it.

Severe consumptive coagulopathy and large intralesional bleeding were corrected with transfusions of plasma, platelets and erythrocytes.

The patient died at 40 days of life due to acute bleeding. Autopsy confirmed the diagnosis of kaposiform haemangioendothelioma $(\mathrm{KH})$.

$\mathrm{KH}$ is a vascular tumour usually present at birth or appearing in early infancy, which can resemble juvenile haemangioma in aspect and shows no tendency to spontaneous involution. It is often associated with Kasabach-Merritt phenomenon, a condition characterised by severe thrombocytopaenic coagulopathy resulting from platelet trapping within the vascular tumour, which can lead to life-threatening haemorrhage (mortality rate 20-30\%). ${ }^{12}$ Several therapeutic regimens, including corticosteroids, chemotherapy, radiotherapy and surgery have been reported, with variable rates of success. ${ }^{1-3}$ Extreme prematurity reduces treatment chances, highly increasing the mortality rate.

\section{Learning points}

Kaposiform haemangioendothelioma is a vascular tumour, usually present at birth, which shows no tendency to spontaneous involution and is often associated with Kasabach-Merritt phenomenon (KMP). ${ }^{12}$

- KMP is a condition characterised by severe thrombocytopaenic coagulopathy resulting from platelet trapping within the vascular tumour and is associated with high mortality rate $(20-30 \%) .^{12}$

- KMP optimal treatment has not yet been established; several therapeutic regimens, including corticosteroids, chemotherapy, radiotherapy and surgery have been reported. ${ }^{1-3}$ Extreme prematurity reduces treatment chances, highly increasing the mortality rate.

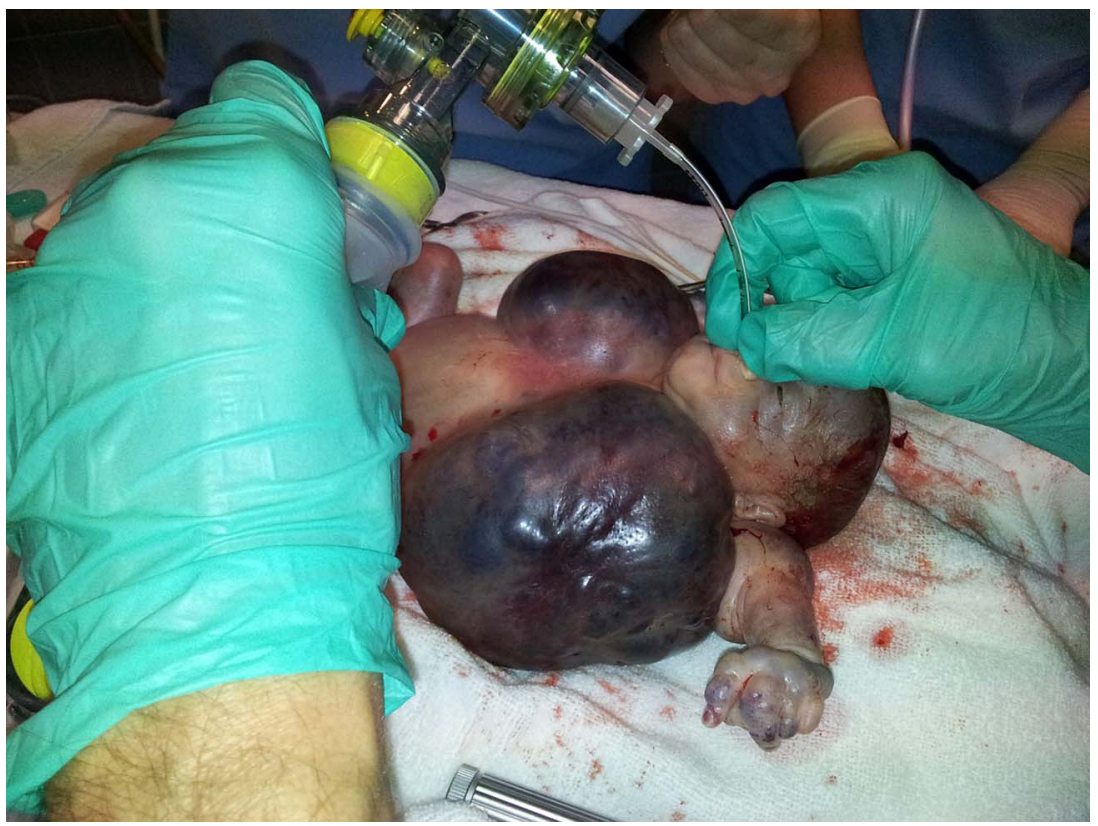

Figure 1 Clinical presentation at birth. 


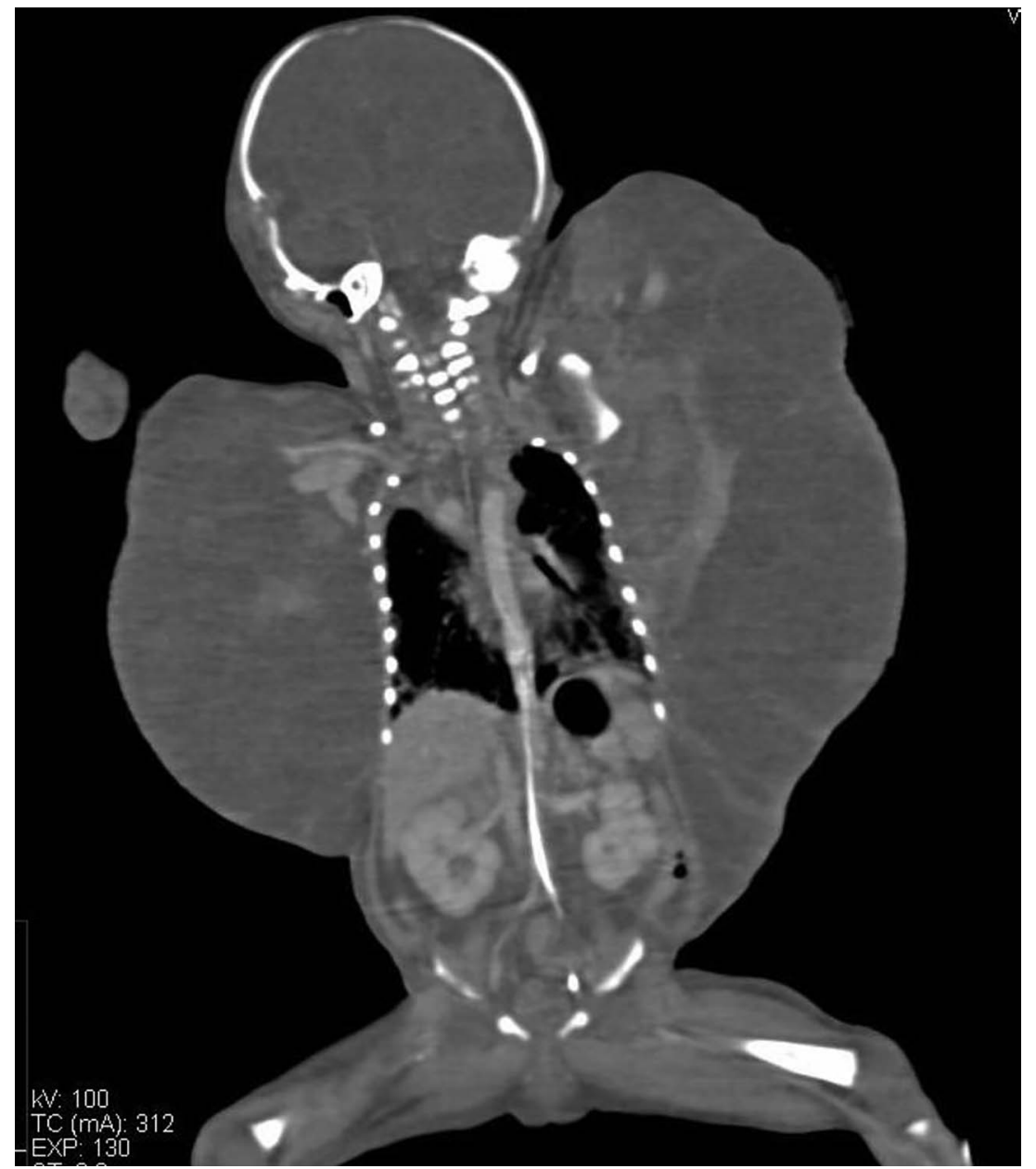

Figure 2 Angio-CT showing the presence of voluminous masses surrounding the thorax.

Contributors The authors are responsible for this case report, have participated in the care and clinical discussion, drafting or revising of the manuscript and have approved the manuscript as submitted.

\section{Competing interests None.}

Patient consent Obtained.

Provenance and peer review Not commissioned; externally peer reviewed.

\section{REFERENCES}

1 Yasui $\mathrm{N}$, Koh $\mathrm{K}$, Kato $\mathrm{M}$, et al. Kasabach-Merritt phenomenon: a report of 11 cases from a single institution. J Pediatr Hematol Oncol 2013;35:554-8.

2 Fernandez-Pineda I, Lopez-Gutierrez JC, Chocarro G, et al. Long-term outcome of vincristine-aspirin-ticlopidine (VAT) therapy for vascular tumors associated with Kasabach-Merritt phenomenon. Pediatr Blood Cancer 2013;60:1478-81.

3 Zhou SY, Li HB, Mao YM, et al. Successful treatment of Kasabach-Merritt syndrome with transarterial embolization and corticosteroids. J Pediatr Surg 2013;48:673-6.

Copyright 2014 BMJ Publishing Group. All rights reserved. For permission to reuse any of this content visit

http://group.bmj.com/group/rights-licensing/permissions.

BMJ Case Report Fellows may re-use this article for personal use and teaching without any further permission.

Become a Fellow of BMJ Case Reports today and you can:

- Submit as many cases as you like

- Enjoy fast sympathetic peer review and rapid publication of accepted articles

- Access all the published articles

- Re-use any of the published material for personal use and teaching without further permission

For information on Institutional Fellowships contact consortiasales@bmjgroup.com

Visit casereports.bmj.com for more articles like this and to become a Fellow 